
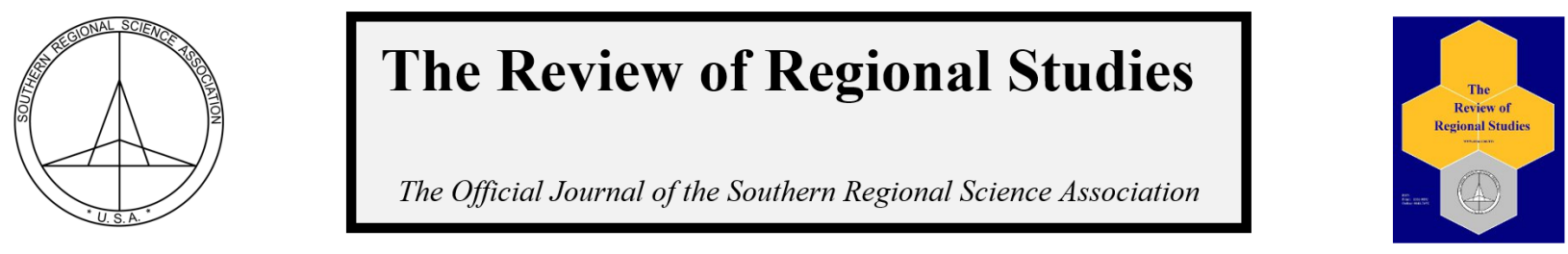

\title{
Measuring Knowledge-capital Stock and Its Relationship with Economic Growth in the Mexican States*
}

\author{
Vicente German-Soto ${ }^{\mathrm{a}}$ and Alma Leticia Rodríguez Hernández ${ }^{\mathrm{b}}$ \\ ${ }^{a}$ Department of Economics, Autonomous University of Coahuila \\ ${ }^{b}$ Coahuila State Government, Auditoría Superior del Estado
}

\begin{abstract}
This work proposes a new technique for measuring knowledge capital that applies the concept of Euclidian distance to factors often considered pillars of knowledge. Importantly, this methodological proposal can suitably treat variables assessed using different measurement units and scales. The empirical exercise considers the 32 Mexican states between 2000 and 2016, with results classifying the economies into high and low knowledge levels and estimates of the link between knowledge and economic growth, confirming the hypothesis of decreasing returns and demonstrating a positive relationship with knowledge capital. The conclusions recommend strengthening knowledge capital in all regions to boost economic growth and transition to a knowledge economy.
\end{abstract}

Keywords: knowledge economy, economic growth, Euclidian distance, regional economics

JEL Codes: C13, C80, O47, R11

\section{INTRODUCTION}

Aiming to create a framework through which countries would be able to build knowledge capital and speed the process of transitioning to a knowledge economy, the World-Bank (2008) proposed a knowledge assessment methodology (KAM) comprising four pillars: institutional regime, education, information infrastructure, and innovation system. Each pillar is assessed using variables that are transformed through a normalization procedure to rank countries according to the absolute values of the variables. However, this calculus can allocate more than one country, either the top or worst normalized position (Chen and Dahlman, 2005).

\footnotetext{
${ }^{*}$ The authors thank to the editors of this journal, two anonymous reviewers for helpful contributions that enriched the final version of this work, and the Autonomous University of Coahuila for support received to carry out this project. Vicente German-Soto is a Faculty of Economics at Autonomous University of Coahuila.Unidad Camporredondo, Edificio "E", entre las calles Av. De los Maestros y David Berlanga, C.P. 25000, Saltillo, México. Alma Leticia Rodríguez Hernández, Coahuila State Government, Auditoría Superior del Estado.Blvd. Fundadores, Col. Real del Sol III, C.P. 25294, Saltillo, Coahuila. Corresponding Author: V. German-Soto, E-mail: vicentegerman@uadec.edu.mx
}

(c) Southern Regional Science Association 2021 ISSN 1553-0892, 0048-49X (online)

www.srsa.org/rrs 
This work proposes measuring knowledge capital by building on these ideas with two innovations. First, a Euclidian distance concept supports this approach, which advantageously focuses all calculations on the progress for each indicator as relative distances. This does not require support from a theory and avoids the scales and units of measurement of the variables and nor does it demand a priori decision-making regarding the weighting of each knowledge factor in the final index. Second, given our interest is in the regional context of a country, our approach works with factors that can differ from those normally constituting each knowledge pillar. Nonetheless, the index remains conducive to any alternative context, such as making comparisons between countries. Thus, although this approach is based on the World Bank's four pillars, the differential regional scope implies certain other variables having been integrated into the final indicator.

Rapid technological, scientific, and innovational societal changes have made the knowledge economy increasingly important in the last twenty years. This heavily impacts the economic, political, and social aspects of life. The knowledge economy's position is such that economic growth cannot presently be understood while ignoring a country's knowledge level (World-Bank, 2008). That is, countries with higher knowledge levels tend to exhibit higher levels of economic development, while countries with lower levels of economic development have also demonstrated lower knowledge levels. The strength of this association has increased in the context of a globalized economy. Given this situation, it seems necessary to elaborate on the indicators that facilitate the measurement of the development of a country's knowledge level and the contribution of knowledge to economic growth. Understanding this relationship will also enable investments in human capital and technology to be carefully planned.

This process of transitioning to knowledge economies is often compared with the transformation engendered by the industrial revolution during the 18th and 19th centuries (Schwab, 2017; Ojanperä et al., 2019). Therefore, the importance of knowledge capital for developing contemporary economies should be emphasized, and further studies on the role of knowledge capital are imperative.

While several studies in the field are concerned with measuring knowledge levels (Chen and Dahlman, 2005; Fan, 2015; Balland and Rigby, 2017), others investigate the channels through which knowledge is disseminated among countries and economies (Dasgupta, 2012; Madsen and Murtin, 2017). Other lines of inquiry investigate the links between knowledge and economic and demographic characteristics (Kuznetsov and Dahlman, 2008; Bar and Leukhina, 2010; Hunt and Gauthier-Loiselle, 2010; Aum et al., 2018) while centering analysis around regional heterogeneity and the forces influencing knowledge production. For van der Wouden and Rigby (2019), two kinds of forces influence knowledge production: inventor density reinforces urban advantages while clusters of firms combine to form social networks. Both shape the architecture of knowledge within cities, with location enabling access to knowledge, making the geography of knowledge relevant (Huggins et al., 2019) in regional contexts where firm heterogeneity significantly impacts the relative importance of knowledge (Grillitsch and Nilsson, 2019). Education and knowledge improve firm soundness, with effects varying according to regional knowledge levels (Abdel Fattah et al., 2020) and differences between knowledge fields such as, for example, natural and social sciences (Fritsch and Aamoucke, 2017).

(C)Southern Regional Science Association 2021. 
Meanwhile, it is increasingly clear that the local context of the knowledge-growth relationship demands investigation. The accumulation of local knowledge has become a critical growth determinant, especially given the removal of cross-border trade barriers has intensified global interactions - in the form of the international division of labor, the free movement of capital and goods, migration, and vastly expanded outsourcing operations - while enabling technology to spread faster, more easily, and at a lower cost. The expansion of global markets has rerouted knowledge transmission from a country-based to a regional scale. During the era of globalization, regions have increasingly appeared on the economic map as their contributions have become critical to this global production strategy. For example, installing corporate entities often requires the careful study of regional capabilities to reduce risks and uncertainty with regard to firm profitability. Thus, regions with a greater local knowledge endowment are better situated to attract investments, demonstrate suitable infrastructure, and, therefore, take advantage of international trade.

All of this implies that studies should consider the local conditions, in terms of productivity and the conduct of the economic activity, for at least two reasons. First, it is necessary to identify regions better prepared to receive investments. Second, it is fundamental to identify strengths, weaknesses, and differences between regions to direct policies that propel economic development. Given knowledge capital's multidimensionality - due to it integrating an array of factors - its interactions and effects are difficult to demonstrate without utilizing certain indicators built for the specific purpose. Accordingly, this work's knowledge economy index (KEI) seeks to improve our understanding of the accumulation of local knowledge and its growth promotion role.

The term knowledge describes a concept shaped by several factors, including education, experience, income, scholarly, training, and learning. However, none of these variables can be considered separately as a complete indicator when assessing a knowledge economy. Instead, each engenders only one component of knowledge. Research on economic growth often utilizes only some of these variables, consequently providing evidence that only partially supports the effect of knowledge on economic growth. Therefore, it seems imperative to develop a measure integrating the greatest possible number of knowledge factors to better approach an understanding of the knowledge economy. Although the World Bank's KAM constitutes an index combining all of these variables, it has yet to be established - in the context of indexes built from such an array of variables - how much each variable contributes to the total index. Another concern is the differential units of measurement for variables.

This proposal overcomes these limitations by using the concept of Euclidian distance, which does not require weighting factors to be defined. Euclidian distance is a canonic measure that, applied to knowledge factors, normalizes the different scales and measurement units of the original values to avoid defining the weight of each variable when estimating the knowledge stock value. This work's proposed combined index constitutes an improvement upon the use of each individual component and relaxes the problem of weighting variables.

Ultimately, this work has two objectives. First, it wants to propose a new technique for measuring knowledge capital at the aggregate economy level; that is, in a macroeconomic context. Using the concept of Euclidian distance, the index enables comparisons between the knowledge level of each economy. Second, utilizing the capacity time- and space-based comparisons enabled by regression models allows for testing of, for example, the hypothesized

(C)Southern Regional Science Association 2021. 
economic growth theory and the contribution of knowledge capital to per-capita income. The proposed approach is applied empirically in the context of the Mexican states between 2000 and 2016, a time frame sufficient to investigate the diminishing returns hypothesis. The empirical results will confirm and validate the consistency and security of the index, including whether it achieves the objective of the knowledge-level assessment.

Although this methodology is applied to the Mexican states, it can be of interest in any setting. In Mexico, for example, more research is needed on economic growth processes using statistical information. For example, the figures for GDP per capita reveal that Mexico has demonstrated little or no economic growth over the past forty years. The 1980s saw an average growth rate of $-0.55 \%$, and a figure just below $1.6 \%$ was recorded for the $1990 \mathrm{~s}$. Between 2000 and 2010, growth was even worse than the previous decade, with an average annual growth rate of $0.12 \%$; however, economic growth improved again to reach an annual average of approximately 1.5\% in recent years (between 2010 and 2018). In 2019, the growth rate was again negative (-0.3\%), and the adverse effects of the COVID-19 pandemic contributed to the considerable negative growth rate of $-8.5 \%$ in $2020 .{ }^{1}$ knowledge could play a strategic role in this pattern, with knowledge replacing previously fundamental investment factors. Given economic growth is currently more heavily based on innovation, knowledge, and an economy's inventive capacity, the present data illuminates Mexico's economic performance.

Following this introduction, Section 2 reviews the literature and discusses the theoretical basis for this work. Section 3 describes the methodological proposal upon which the work rests, comparing it to the World Bank's KAM. Section 4 provides estimates and empirical results, and Section 5 tests the new index in the context of the relationship between the knowledge and economic growth of Mexican states. Concluding remarks are provided in Section 6.

\section{THEORETICAL BACKGROUND AND LITERATURE REVIEW}

The growth models provided by Romer (1986, 1990) and Lucas (1988) indicate that the accumulation of knowledge is a key factor in the progress of modern societies. Meanwhile, more recent studies on growth have clearly established that knowledge accumulation is an important determinant for economic performance in both the national and regional domains (Chen and Dahlman, 2005; Paci and Usai, 2009; Fischer et al., 2009; LeSage and Fischer, 2009; Balland and Rigby, 2017; Fritsch and Aamoucke, 2017). For example, Cader (2008) reviews the evolution of knowledge-based economies in the U.S.'s non-farming industries, finding that knowledge-based industries notably increased between 1991 and 2001, with technology playing a vital role. Meanwhile, Jensen (2008) demonstrates the emergence of a knowledge society within the chemical and electrical industries, and Fritsch and Slavtchev (2010) compare the specialization of high-innovation industries between regions. Notably, the gradual progress of industries towards dynamic knowledge intensity has necessitated measurement of knowledge in service of increased competitiveness, with Westeren (2008) concluding that knowledge has become not only a strategic device for firm competitiveness

${ }^{1}$ Own estimates with data on GDP from INEGI (see www.inegi.org.mx, accessed by February 20, 2021). Series at constant prices of 2013.

(C)Southern Regional Science Association 2021. 
but also critical for regional innovation and patent production (Innocenti et al., 2020).

Difficulties measuring knowledge capital have been constant among researchers, with some authors considering patents and citations of patents suitable mechanisms, due to being rich knowledge sources and enabling effective knowledge diffusion through (generally) easy dissemination through international trade channels ( $\mathrm{Hu}, 2009$; Wang et al., 2012; Gould and Panterov, 2017; Inoue et al., 2019). This enables rapid dissemination of knowledge to economies or regions that have not invested in research and development (Malecki, 2010; Dressler, 2012; Huggins et al., 2019). Additionally, Dasgupta (2012) demonstrates that diffusion of knowledge is a product of worker mobility, Sum and Jessop (2013) show that it corresponds to higher education, and Fritsch and Aamoucke (2017) indicate that it arises from the differential effects of various types of higher education institutions.

This discussion has prompted several studies dedicated to measures of the knowledge levels of various economies. For example, Chen and Dahlman (2005) built an index using the World Bank's suggested pillars of a knowledge-based economy while (Fan, 2015) created a novel ranking of nations and states according to knowledge evaluation, and Balland and Rigby (2017) measured knowledge accumulation using a complexity index. The results of that proposal applied to U.S. data demonstrated that knowledge features broad geographic variations and is spatially sticky. Meanwhile, digital platforms have also offered new insights into building knowledge economies (Ojanperä et al., 2019).

Elsewhere, huallachain (2007) uses an inter-regional convergence framework to investigate how knowledge-based economies affect regional economic performance in the U.S., with the results demonstrating a change in the pace of interstate convergence, with growth associated with states' knowledge-based characteristics. In contrast, Zhou et al. (2019) use the convergence concept to investigate this process among the scientific disciplines, and Barkhordari et al. (2019) examine pillars widely related to knowledge and economic growth in the context of framework similar to that employed by J Barro and Sala-i Martin (2004).

\section{METHODOLOGY OF KNOWLEDGE ECONOMY INDEX AND EMPIR- ICAL MODEL}

\subsection{World Bank KAM proposal}

The World Bank's KAM (2008) includes 83 variables categorized according to four pillars of knowledge economies: institutional regime (it incentivizes using existing knowledge and producing new knowledge), education (it enables the creation and sharing of knowledge), information infrastructure (it disseminates information and facilitates knowledge), and innovation system (it features the ultimate objective of creating new knowledge). The KAM is motivated by the notion of a framework country can use to build knowledge capital and accelerate the process of transitioning to a knowledge economy. For the institutional regime, indicators include tariff and non-tariff barriers, regulatory quality, and the rule of law. For education, while the gamma of educative variables is suitable, the World Bank specifically uses adult literacy rate and gross secondary (tertiary) enrollment rate. Meanwhile, infrastructure variables include the number of telephones, computers, and internet users, and the innovation pillar integrates indicators such as patents, scientific research, and royalty

(C)Southern Regional Science Association 2021. 
payments. The corresponding KEI enables structural comparisons between 140 countries, of which 100 are developing countries and the remaining belong to the Organization for Economic Co-Operation and Development (OECD). According to the World-Bank (2008), global economies require knowledge accumulation as a basis for continuous growth. The KEI features notable advantages, such as enabling the identification of strengths and weaknesses that can illustrate areas requiring careful planning to capitalize on the knowledge revolution in the global economic context. Accordingly, the aforementioned four pillars constitute the basis for transitioning to a knowledge economy (World-Bank, 2008).

The first step in the KAM is building a KEI that considers strengths and weaknesses in service of articulating goals and investments that can improve knowledge stock. The second step is normalizing all 83 variables to represent them on a 0-10 scales (weakest to strongest performance), a step enabling countries to be ranked according to their relative knowledge performance (Chen and Dahlman, 2005).

\subsection{The KAM proposal for the Mexican states}

The World Bank's KAM (WB-KAM) inspired the KAM this work proposes for the Mexican states (Table 1), which features two main differences. First, there are more limitations on raw data at the regional level; thus, the index employs 15 variables distributed among the four pillars that are available for all 32 Mexican states.

Education is a critical tool for knowledge acquisition, and its accessibility is essential for societies. People accumulate knowledge through life's basic tasks of reading, writing, and solving problems(Madsen and Murtin, 2017). Accordingly, providing primary education for the population is critical for a country to transition to a knowledge economy, with a lack of basic education complicating the possibility of transitioning. Research has linked education and knowledge to growth and economic performance, highlighting how investment in education favors growth by enabling the population to accumulate knowledge (Judson, 1998; Keller, 2006; Hanushek and Woessmann, 2008; Waldorf, 2009; Madsen and Murtin, 2017; Lenkei et al., 2018).

Accordingly, education, population characteristics, and human resources indicators are integrated into the first pillar. Years of schooling provide information about a population's level of knowledge, with a higher average education level indicating a higher knowledge level. The second measure, the adult literacy rate, suggests the importance of a population having reading and writing skills, which represent the first step towards accumulating and disseminating knowledge (Madsen and Murtin, 2017).

Some authors argue that population characteristics dictate the knowledge that a society can accumulate, with Bar and Leukhina (2010) identifying a negative relationship between mortality rate, knowledge, and productivity growth, and Hunt and Gauthier-Loiselle (2010) examining the impact of migrant skills on patents per capita to suggest the easier transfer of knowledge between countries. Therefore, it is worth investigating both whether a reduced mortality rate (among 18 to 60 year-olds) could be positively correlated with knowledge creation and whether immigration has implications for knowledge production. However, given the lack of available data on immigrant skills, net immigration is used, assuming that knowledge diminishes when the immigration rate is negative and increases when it is positive.

(C)Southern Regional Science Association 2021. 
Table 1: Pillars of the Knowledge Economy for the Mexican States

\begin{tabular}{ll}
\hline \hline Pillar & Indicator \\
\hline Education and human resources & Years of schooling \\
& Adult literacy rate \\
& Mortality rate (among 18-60 year-olds) per 10,000 peo- \\
& ple \\
& Net migration rate \\
& Scholarships per 100 students in public universities \\
& Gross secondary enrollment rate \\
& Gross tertiary enrollment rate \\
& Professors per 100 students in tertiary education \\
& Researchers per 100,000 people \\
& Accumulated patents per 100,000 people \\
& Mobile phones per 100 people \\
Innovation system & Computers per 1,000 people \\
Information infrastructure & Citizen participation in electoral processes \\
Institutional regime & Public revenue \\
& Government's ability to promote the flourishing of busi- \\
& ness activity (FDI/GDP) \\
\hline
\end{tabular}

Source: Author's own elaboration.

(C)Southern Regional Science Association 2021. 
According to Kuznetsov and Dahlman (2008), an educated and trained labor force is necessary to take advantage of the potential of new knowledge and accelerated technological change. Elsewhere, Fritsch and Aamoucke (2017) observe that various scientific fields differentially impact innovative activity, and Grillitsch and Nilsson (2019) consider education to be an important source for knowledge externalities and to highlight between-firm heterogeneity. For Rim et al. (2019), education is the pillar most directly related to the knowledge economy, differentially affecting firm benefits and regional growth, suggesting the need for more efficient ways of conducting spending on education based on the idea that the entire population can participate in knowledge transfer.

As suggested, this process also incorporates human resources, from which four indicators are derived: scholarships per 100 students in public universities, gross secondary enrollment rate, gross tertiary enrollment rate, and professors per 100 students in tertiary education. These indicators include at least three of the four types of knowledge Lundvall and Johnson (1994) describe as necessary for a knowledge economy, namely, know-what, know-who, and know-why. In Mexico, scholarships have represented a clear and consistent public policy that seeks to improve the population's education level. Such scholarships are primarily aimed at lower socio-economic classes, enabling students to access undergraduate and advanced education, such as postgraduate studies, and constitute an important channel for the knowledge-capital generation.

The innovation system pillar is measured by the numbers of researchers and patents, which are both expressed per 100,000 people. Innovation has been identified with the rapid growth exhibited by certain emergent economies and tends to be a key factor for economies lacking growth (OECD, 2009). It is particularly relevant for Mexico, where open trade requires domestic firms to compete with foreign firms.

The information infrastructure pillar enables the dissemination of knowledge, meaning economies with the largest and best infrastructure and communications technology also accumulate more knowledge. Mobile phone technology enables the creation of a socially dispersed network of useful information, which contributes to enhancing collective knowledge. A similar process occurs with computer use, with societies more committed to using computers to complete tasks also featuring faster and more efficient knowledge transfer. For example, according to David (2000), computers are very useful for firms because they can improve decision-making. Additionally, information and communications technologies (ICT) are key for the management and governance of modern-day societies (Rabari and Storper, 2015).

Finally, this study's KAM approaches the institutional regime pillar through three indicators: citizen participation in electoral processes, public revenue, and the ability of the local governments to promote the flourishing of business activity, which was estimated by comparing foreign direct investment to total production (gross state product). ${ }^{2}$

The second main difference between this study's KAM and the WB-KAM is methodological. The WB-KAM initially featured a KEI comprising 12 indicators that are averaged from their normalized values using a 1-10 scale - according to the World-Bank (2008) "a KEI score that is close to 10 implies relatively good development of the four knowledge economy pillars" - although that number and the number of countries covered has been continuously

\footnotetext{
${ }^{2}$ The source of data for the institutional regime is Mexican Institute for Competitiveness (2020).
} 
expanded and updated. According to Chen and Dahlman (2005), to treat different value ranges, the normalization process categorizes all variables from weakest to strongest and then ranks countries on an ordinal scale. In contrast, this work's KAM combines indicators to produce a novel KEI that uses the metric unit of Euclidian distance to describe the overall performance of each region relative to the performance of the remaining regions, precluding the need to produce rankings and normalize scores. This strategy has technical advantages because it weighs scores, avoiding the extreme values implied by the use of a simple arithmetic mean.

The next section explains this idea. However, it is first necessary to further investigate the variables - one way of illustrating the performance of knowledge indicators in each state's basic scorecard spider chart. Accordingly, Figure 1 shows the values for the initial and final years in relative terms, ${ }^{3}$ with a bigger or fuller spider chart indicating a better-positioned economy.

Overall, the Ciudad de México is strongest for several knowledge pillars and indicators, including infrastructure, education, patents, professional services in education, and institutional regime. In the database, the Ciudad de México leads computers per capita, researchers per capita, number of patents per capita, and its citizens have more years of schooling and a higher adult literacy rate.

Analysis of temporal changes demonstrates that while the Ciudad de México maintains its leadership position (with almost no change perceived), the improvements of some states have reduced the differences between them and the capital.

Immigration is the only indicator for which the Ciudad de México is not at the forefront, a function of its expulsing people during this period through a policy aimed at deconcentrating in service of reducing the negative externalities associated with its large size. Also, it should be noted that certain Mexican states demonstrate problems improving their performance for indicators regarding professors per 100 students in tertiary education and scholarships per 100 students in public universities, as well as numbers of researchers and patents, indicators related to scientific activity, technology, and higher education. Nonetheless, in general, they have improved their indicators between 2000 and 2016, with the spider charts for 2016 fuller than those for 2000 in almost all cases, suggesting that knowledge capital has increased, as anticipated by the theory.

\subsection{A KAM index based on Euclidian distance}

The aim is to define a simple index reflecting the contribution to the knowledge of a set of variables that enable comparison of the knowledge level achieved by economies integrating a similar system, such as the regions of a country. This can identify economies with higher and lower knowledge levels. To achieve this, it is necessary to measure the gaps in knowledge.

It is considered that $\mathrm{z}$ dimensions shape the knowledge level of any economy. With each dimension participating based on their knowledge stock, this amount is expected to vary between economies, producing different knowledge levels for different economies. For knowledge measurement, the KAM considers diverse variables integrating knowledge capital and

\footnotetext{
${ }^{3}$ As is explained below, indicator values are relative to the maximum value for each year and state.
} 
Figure 1: The Basic Scorecard Spider Chart for 2000 and 2016

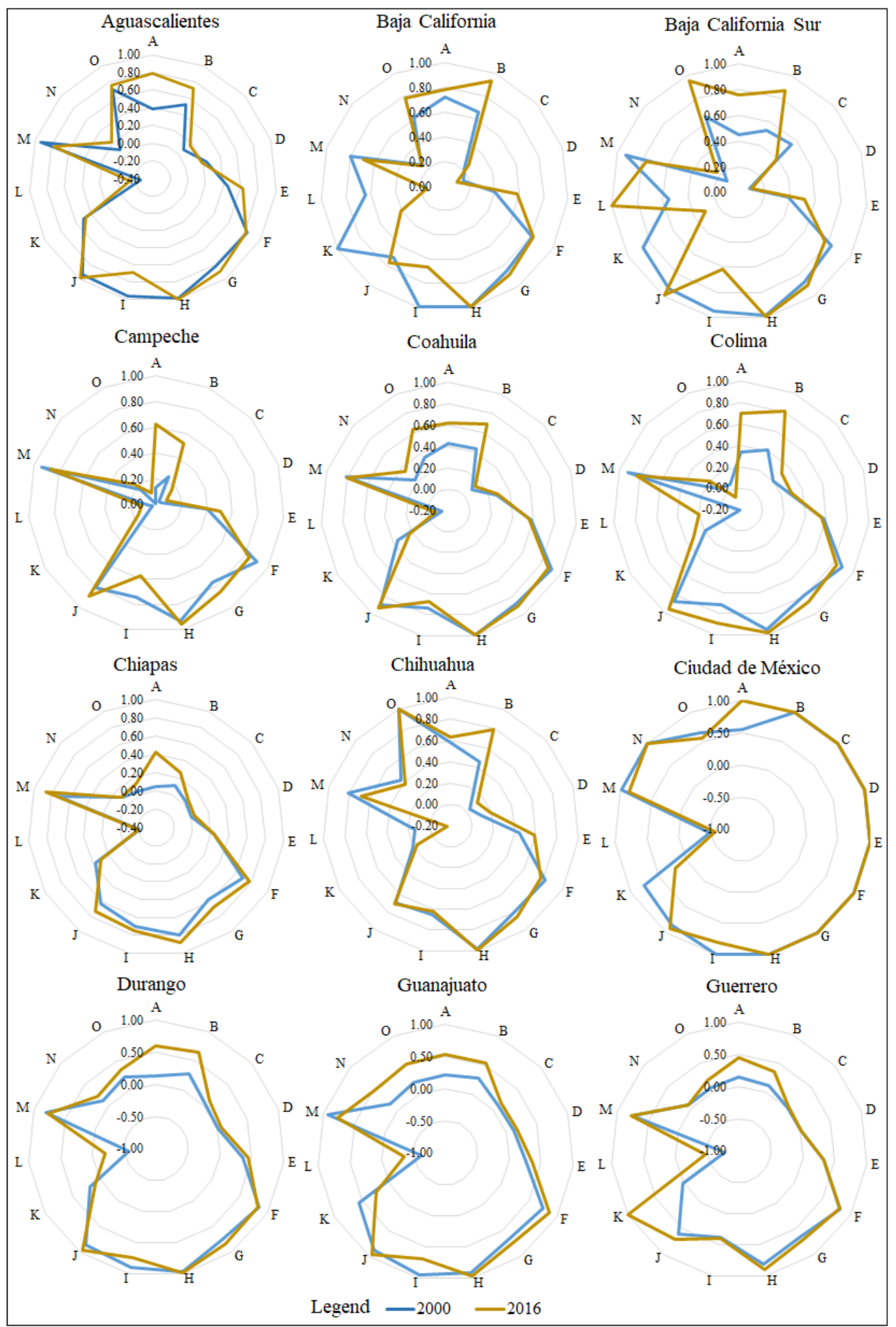

(C)Southern Regional Science Association 2021. 


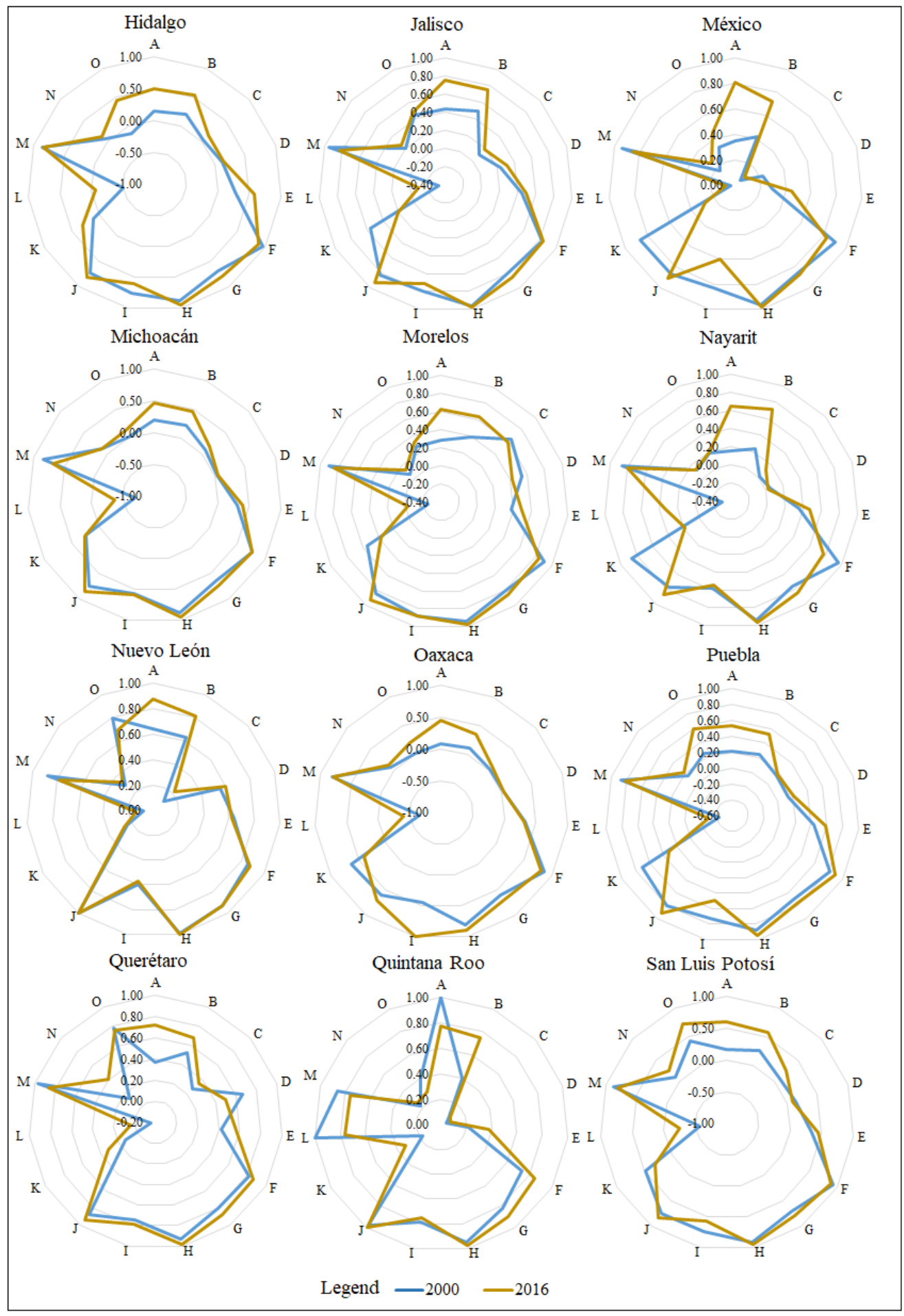

(C)Southern Regional Science Association 2021. 


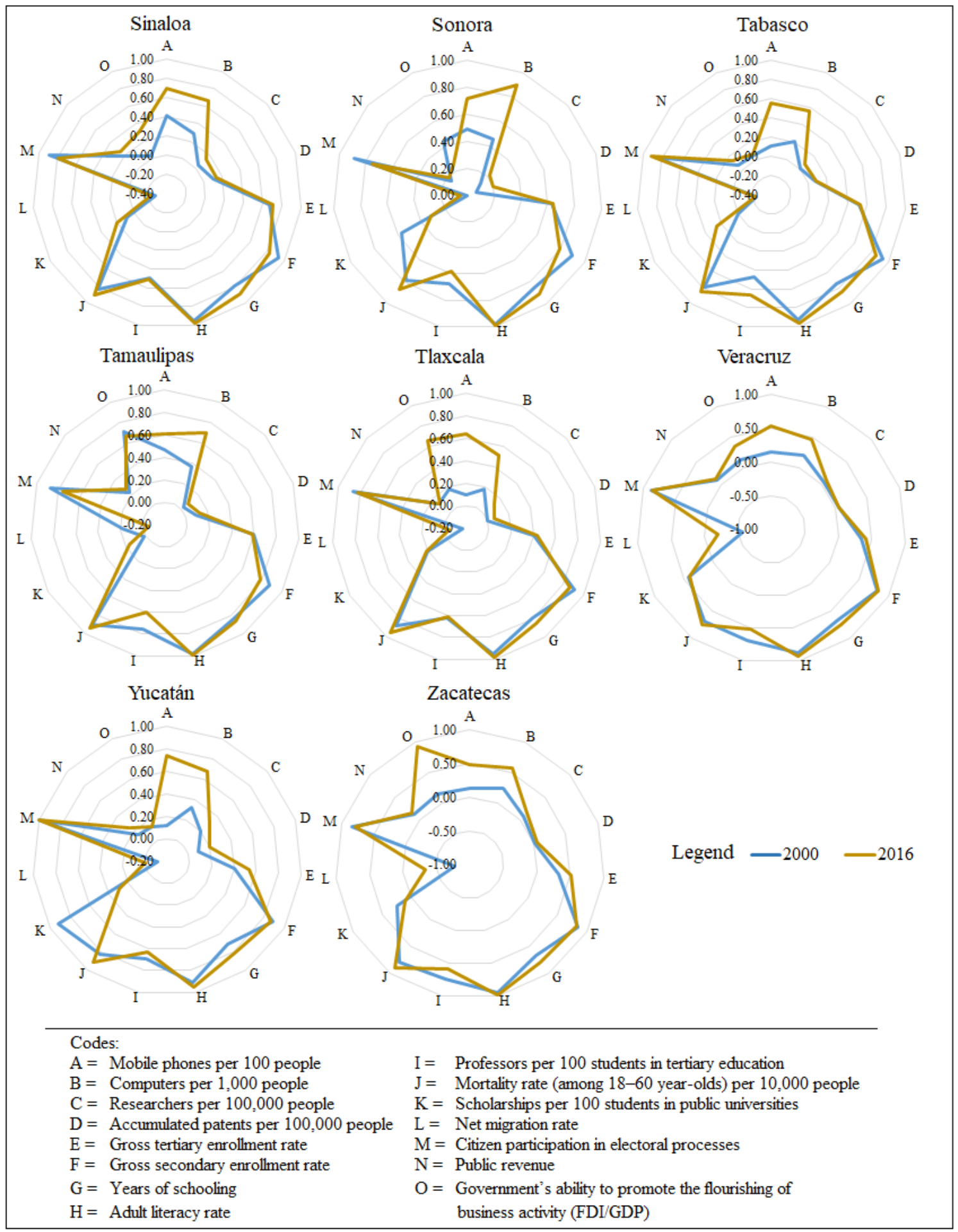

Source: Author's own elaboration.

(C)Southern Regional Science Association 2021. 
the different scales and units of measurement, with the recommendation that transforming this set of indicators preserves the distances such that scales do not influence the final index.

Consider a hypothetical case in which the knowledge level is shaped by only two inputs, $\mathrm{x}$ and y. Now, assume that the economic system comprises only two economies, $A$ and $B$. Both economies use a determined amount of the x-input and another amount of the y-input in the process of knowledge accumulation. Figure 2 assumes a determined knowledge level for each economy and illustrates the distance, in terms of knowledge, between the two economies. The interest here is measuring the distance between $A$ and $B$ and between $B$ and $A$, which, in this case, is the same because there are only two economies.

Figure 2: Knowledge Distance between Two Economies in the Vector Space of Two Dimensions

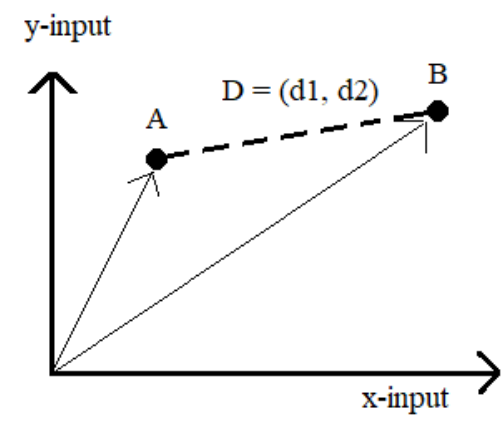

Source: Author's own elaboration.

However, to expand the system to three economies (considering the third economy, $C$ would imply measuring, for each economy, the relative distance between all three economies in the vector space (Figure 3). The corresponding index should average the distance between all three. That is, for economy $A$, the index should indicate the distance from both $B$ and $C$. For $B$, it should indicate the distance from both $A$ and $C$, and, for $C$, it should indicate the distance from both $A$ and $B$. It would be incorrect to consider the distance between only two economies when a third economy is present.

Generalizing, a system integrated by $k$-economies considers the relative distance generated by all three combinations formed by the $k$-economies, with the final index averaging comparative knowledge-level prevalence between all of the economies. The term comparatively is used because the KEI measures the average distance between the knowledge level of one economy in relation to the corresponding knowledge level of all of the other economies.

Given it is possible to measure the knowledge level using real numbers, this belongs to the vector space, with the Euclidian distance norm suited to investigating the different levels of knowledge. Letting $D_{A B}$ denote the distance between $A$ and $B$ in the vector space of two dimensions,

$$
\left\|D_{A B}\right\|=\left(\sum_{i=1}^{2} f_{i}^{p}\right)^{\frac{1}{p}} \quad \text { where } p \geq 1
$$

If $p=1$, then equation (1) is a rectangular distance between $A$ and $B$; however, if $p$ (C)Southern Regional Science Association 2021. 
$=2$, equation (1) constitutes the Euclidian distance (Love and Morris, 1975). Here $f_{i}$ is a norm function that characterizes the distance from $A$ to $B$ and represents an alternative KEI. Generalizing the vector space of $n$-dimensions, the vector

$$
D_{A B}=\left(d_{1}, d_{2}, \ldots, d_{n}\right)
$$

refers to the $n$-dimensional distance from $A$ to $B$, with its norm given by

$$
\left\|D_{A B}\right\|=\left(\sum_{i=1}^{n} f_{i}^{p}\right)^{\frac{1}{p}} \quad \text { where } p=2
$$

At this level of analysis, it is necessary to define a particular norm function characterizing the idea of comparing knowledge between economies. However, note that equation (3) satisfies the properties of Euclidian length (Simon and Blume, 1994; Zarinbal, 2009):

$$
\begin{gathered}
\text { Possitivity: }\left\|D_{A B}\right\| \geq 0 \text { for all } A, B \in \text { vector space } \\
\text { Definition : }\left\|D_{A B}\right\|=0 \text { if and only if } A, B=0 \\
\text { Symmetry : }\left\|r D_{A B}\right\|=|r|\left\|r D_{A B}\right\| \quad \text { where } r \text { is a constant } \\
\text { Triangular inequality : }\left\|D_{A B}(A B+w)\right\| \leq\left\|D_{A B}\right\|+\left\|D_{w}\right\|
\end{gathered}
$$

where $w$ is any other point in the vector space.

Now, a functional form must be given to equation (3). However, two additional details remain necessary. First, the index should consider a benchmark supporting the notion of distance to validate the comparisons. One possibility is choosing the economy with the maximum value in a certain dimension; that is, the leading economy in that dimension, which implies that the "leader" would not necessarily be the same in each time and dimension. Second, the methodological proposal should consider adopting a convenient specification for (3), such that the further an economy is from the leader, the less knowledge capital it has. Leaving equation (3) as defined produces the opposite because only the gap is measured (the distance from the leader). Here, it is worthwhile defining $f_{i}$ in (3) as a reciprocal function,

Figure 3: Knowledge Distance between Three Economies in the Vector Space of Two Dimensions

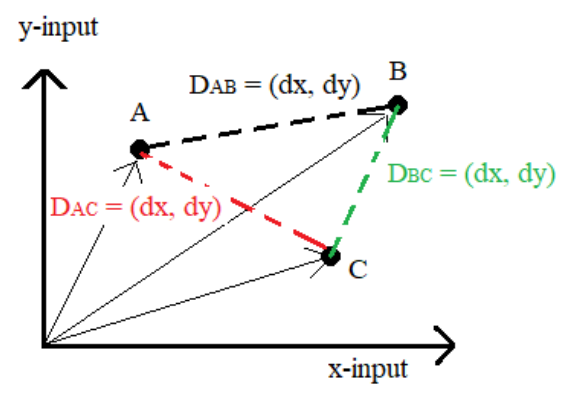

Source: Author's own elaboration.

(C)Southern Regional Science Association 2021. 
with a greater distance implying less knowledge with respect to the leader. Assuming $p=2$ in $(3)$, then

$$
\left\|D_{A B}\right\|=\left(\sum_{i=1}^{n} \frac{1}{f_{i}^{2}}\right)^{\frac{1}{2}}
$$

where $i$ is an indicator of dimension, and it is considered that $i=1,2, \ldots, n$. Letting $\left\|D_{L, k}\right\|$ denote the Euclidian distance between the leading economy (denoted by $L$ ) and the $k$-th economy in comparison, the denominator in (4) can be expressed as developed notation:

$$
\left\|D_{L, k}\right\|=\left[\frac{1}{\left(L_{1}-k_{1}\right)^{2}}+\frac{1}{\left(L_{2}-k_{2}\right)^{2}}+\ldots+\frac{1}{\left(L_{n}-k_{n}\right)^{2}}\right]^{\frac{1}{2}}
$$

In the vector space of $n$ dimensions, equation (5) calculates the Euclidian-distance norm between the leader in each dimension and the $k$-th economy. The reciprocal function associates a longer distance with less knowledge capital. At this level of analysis, it should be observed that in cases where the leading and $k$-th economies are the same, the denominator value is zero. To avoid this mathematical error, $L_{i}$ is defined as $L_{i}=\max k_{i}+1$, such that when the $k$-th economy is the leading economy, the corresponding denominator adopts the unit value. In the hypothetical case that one economy leads in all dimensions, each sum in (5) would be the unit, with the total value in brackets corresponding to the number of dimensions considered in the exercise. For this reason, the final index is normalized to a maximum value equal to the total number of dimensions (indicators) considered in equation (5). That is, equation (5) features a higher limit that is equal to the number of dimensions. For instance, if $n$ indicators shape the index, the maximum possible value in (5) would be $n$; meanwhile, as the lower limit approaches zero as the economy increasingly moves away from the benchmark. In the empirical exercises, equation (5) is estimated for each economy and time corresponding to the vector space.

\section{THE KNOWLEDGE ECONOMY INDEX BASED THE DISTANCE FOR THE MEXICAN STATES: ESTIMATES AND ANALYSIS}

For the empirical exercise, equation (5) is estimated for the 32 Mexican states for the period 2000-2016 using the set of indicators presented in Table 1. As discussed in the methodology section, the maximum value for each year and indicator are calculated to constitute a benchmark, with this work's appendix in Table A1 reporting the total matrix of values in alphabetical order and Figure 4 providing a global view of the KEI changes between 2000 and 2016.

The first five locations in both the top and bottom parts of the appendix registered almost no movement, suggesting that the economies with the highest and lowest levels of knowledge are the same. The top part indicates the Ciudad de México leading throughout the period, a logical result given the capital city's concentration of knowledge through being the largest metropolitan area and the location with the most corporate and government dependencies. In the database, the Ciudad de México records the best average performances for almost all indicators, anticipating it having the highest index. Other top-ranked states are Nuevo 
León, Baja California Sur, Quintana Roo, Colima, and Morelos. While the results for the first two states were expected due to their being the best positioned economically, the final three were not. However, there are explanations for each: Morelos has made notable progress through the recent proliferation of academic research centers, and both Quintana Roo and Colima feature scarce populations, upwardly affecting the index.

Poorer states are mostly located in the south of the country and comprise the bottom part of the table in the appendix. These states include Oaxaca, Guerrero, Chiapas, and Michoacán, states other studies on Mexican regions have generally identified as the poorest and most economically lagging (Carrion-i Silvestre and German-Soto, 2007).

In Figure 4, the Mexican states are presented in a scatter plot showing the KEIs for the initial and final years of the period. The horizontal axis plots the KEI for 2000, and the vertical axis plots the KEI for 2016. The diagonal line indicates the locus point, where both values are equal, indicating states for which the data shows no change. Figure 4 also reveals the localization of some states (in a shorter form).

States appearing above the diagonal line notably improved their KEI between 2000 and 2016, with states appearing below the diagonal line recording a diminished KEI. Using this classification, it was possible to observe the advances made by these economies. For example, Ciudad de México (CDMX), Quintana Roo (QRO), Tamaulipas (TAM), and Estado de México (MEX) are on the diagonal line, ${ }^{4}$ indicating, as discussed, an absence of significant KEI changes. However, a significant group of economies appears above the diagonal line (27 out of 32), including Baja California Sur (BCS), Nuevo León (NL), Morelos (MOR), Colima (COL), Querétaro (QUE), Jalisco (JAL), and Sinaloa (SIN). This suggests that the KEIs of these economies have improved. Only Baja California (BC) is below the diagonal line, indicating, uniquely, an overall decrease of its KEI.

Notably, the KEI scatter plot indicates that there are three broad groups of states in terms of their development towards a knowledge economy. First, the top-right corner of the scatter plot features economies in advanced development stages, with only Ciudad de México (CDMX) qualifying, as the most developed in knowledge-economy terms. The second group of economies is focused around the center of the scatter plot and contains most states, including Nuevo León (NL), Baja California Sur (BCS), Morelos (MOR), Quintana Roo (QRO), Baja California (BC), Aguascalientes (AGS), and Querétaro (QUE). This category might be said to include economies clearly transitioning to a knowledge economy.

The third group features the economies that are lagging in terms of knowledge, which appear around the bottom-left corner of the scatter plot. This group includes low-income states such as Oaxaca (OAX), Guerrero (GRO), Chiapas (CHI), Veracruz (VER), and Michoacán (MIC). These economies are geographically located in the south of Mexico. Although Figure 4 highlights relative KEI performance, the remarkable difference between the Ciudad de México and the rest of the states is noteworthy, with the capital being the location with, among other factors, the highest economic development, highest incomes, highest education levels, and most foreign direct investment. Its knowledge-economy distance from other states is substantial, a fact effectively captured by the KEI.

\footnotetext{
${ }^{4}$ Although CDMX is below the line, it is very close and features the highest value.
}

(C)Southern Regional Science Association 2021. 
Figure 4: Knowledge Economy Indices for the Mexican States (Comparison between 2000 and 2016)

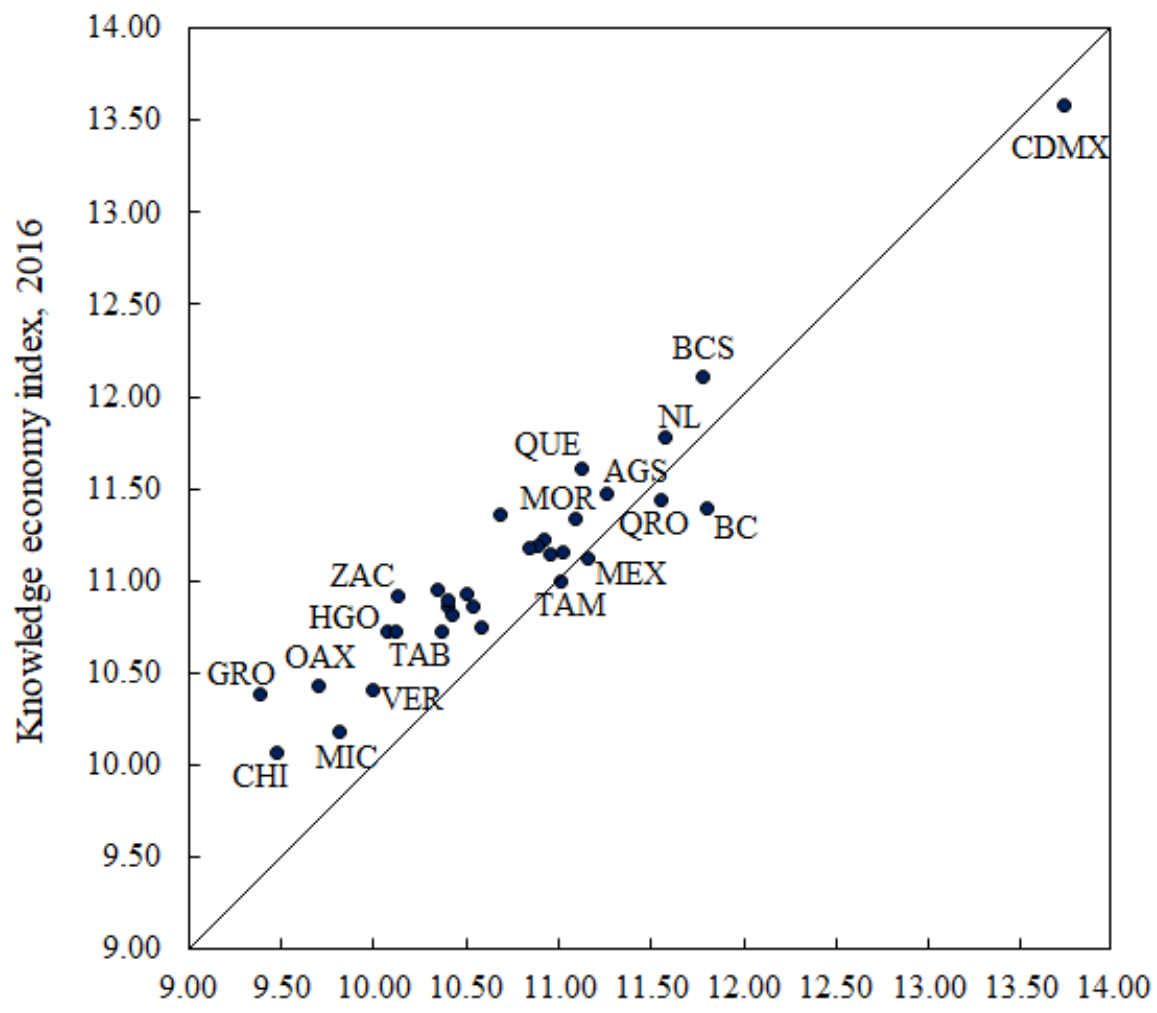

Knowledge economy index, 2000

Source: Author's own elaboration.

\section{THE RELATIONSHIP BETWEEN KNOWLEDGE AND GROWTH ACROSS MEXICAN STATES}

The neoclassical theory of economic growth affirms that population growth, investment rates (physical capital stock), and human capital (e.g., education and knowledge) determine an economy's per-capita income level (Mankiw et al., 1992; J Barro and Sala-i Martin, 2004). Given these factors vary between economies, they also produce different economic growth rates. Higher rates of investment and human capital make an economy richer, with poorer economies tending to present low rates for these determinants. Several empirical studies have found that more than half of the cross-section variation in income per capita can be explained by this set of factors (Mankiw et al., 1992; Caselli et al., 1996; Swamy and Fikkert, 2002; Yamarik, 2011).

Given these variables determine the steady-state level of income, economies far from achieving their steady-state experience increased growth rates when their fundamental variables increase. This theory has been widely tested through both international comparisons and regional-level studies (Badinger et al., 2004; Carrion-i Silvestre and German-Soto, 2007; Yamarik, 2011).

(C)Southern Regional Science Association 2021. 
Therefore, studying the Mexican case using our KEI in addition to factors such as the physical capital stock in a production function is of considerable interest. This approach uses the dependent variable of logarithmic difference in GDP per capita between 2000 and 2016. For the physical capital stock series, although Mexican states lack comparable and continuous investment data covering the overall economy, it is possible to use a capital stock series delimited to only the industrial sector, motivated by the notion that the most intensive productive-capital-use sectors guide the process of capital accumulation and its role on economic growth. ${ }^{5}$ German-Soto (2008) generated this series by calculating the average age of the capital stock using an empirical regression model that considered the relationship between investment rates and employment, consequently capturing regional tendencies followed by the physical capital stock. Accordingly, this indicator constitutes a suitable proxy of the investment level in the state economies.

Before discussing the regression results, Table 2 reports the basic correlations between the main variables. Here, our interest is demonstrating evidence of the impact of knowledge level on economic growth, with statistical description conducted for the overall sample (32 states), for states with a high propensity towards knowledge building (the top five states), and for states with a low propensity (the bottom five states), according to the Figure 4.

Table 2: Basic Correlations between Variables

\begin{tabular}{|c|c|c|c|}
\hline & $\begin{array}{l}\text { Economic } \\
\text { growth }\end{array}$ & $\begin{array}{l}\text { Knowledge } \\
\text { index }\end{array}$ & Capital stock \\
\hline & \multicolumn{3}{|c|}{ Overall sample } \\
\hline $\begin{array}{l}\text { Economic } \\
\text { growth }\end{array}$ & \multicolumn{3}{|l|}{1} \\
\hline $\begin{array}{l}\text { Knowledge } \\
\text { index }\end{array}$ & 0.4579 & \multicolumn{2}{|l|}{1} \\
\hline Capital stock & \multicolumn{3}{|c|}{ High propensity sample } \\
\hline $\begin{array}{l}\text { Economic } \\
\text { growth }\end{array}$ & \multicolumn{3}{|l|}{1} \\
\hline $\begin{array}{l}\text { Knowledge } \\
\text { index }\end{array}$ & 0.7245 & \multicolumn{2}{|l|}{1} \\
\hline Capital stock & \multicolumn{3}{|c|}{ Low propensity sample } \\
\hline $\begin{array}{l}\text { Economic } \\
\text { growth }\end{array}$ & 1 & & \\
\hline $\begin{array}{l}\text { Knowledge } \\
\text { index }\end{array}$ & 0.7226 & 1 & \\
\hline Capital stock & 0.7285 & 0.3076 & 1 \\
\hline
\end{tabular}

Source: Author's own elaboration.

Although correlations with economic growth are positive and strong, associations are

${ }^{5}$ According to German-Soto (2008), the industrial sector includes mining, electricity, gas, and water, as well as the manufacturing sector; these are often considered economic base sectors.

(C)Southern Regional Science Association 2021. 
greater in the high- and low-propensity samples. A comparison between high- and lowpropensity samples indicates similar correlations with the KEI, with capital stock stronger for the low-propensity sample.

Additional evidence of the KEI's relationship with economic growth is presented in Figure 5 , demonstrating that the KEI is a good predictor of economic performance, anticipating regression analyses reinforcing the visual inspection.

The regression analyses were conducted from several perspectives. First, assuming that variables are independent of region-specific factors shifting the production function, it is possible to use ordinary least squares (OLS). The regression labeled R1 in Table 3 reports estimates from a cross-section structure, with growth rates between 2000 and 2016 compared with the levels of the explicative variables and the initial per-capita income value $\left(Y_{t,-1}\right)$. The results adapted with efficacy to the production function. Estimates indicate a convergence speed of 2.6\% among Mexican states during the period 2000-2016, with the signs for knowledge and capital stock indicating high significance. Knowledge capital is more important for economic growth than capital stock in every sample.

Figure 5: Knowledge Economy Index and Gross State Product Per

Capita, 2000

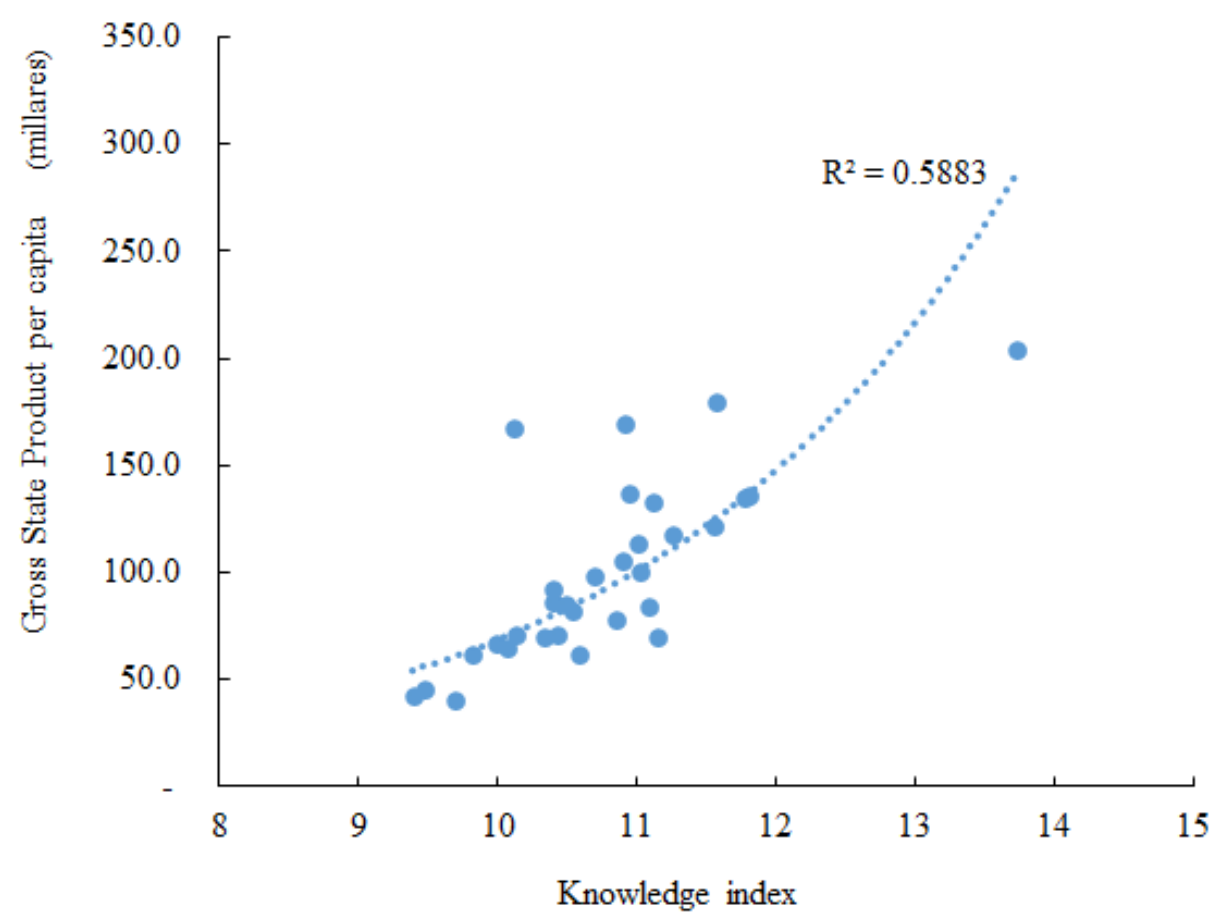

Source: Author's own elaboration.

However, given the model predicts not only the signs but also the magnitudes of the coefficients, it is important to check the consistency of the OLS estimates. With this objective, we consider an annual panel data structure to examine the contribution of the factors not only to the overall sample but also to the high- and low-propensity samples (regressions R2 to R4). Heteroscedasticity is expected; thus, the estimates use the generalized least squares 
(GLS) approach using cross-section weights. For the overall sample, estimates of factor coefficients are higher than those obtained using OLS, while the convergence speed is slower (near to zero). Differences in the estimates could be explained by the correction of the cross-section heterogeneity. The estimates reported for the high- and low-propensity samples emphasize the differences between advanced and lagging economies. The values for factors contributing to the low-propensity sample are higher than the values for the high-propensity sample, a result confirming the hypothesis of diminishing returns for Mexico. Low-propensity states start from lower levels and therefore represent a higher convergence rate. Accordingly, and as expected, the accumulation of knowledge stands out in this comparison.

Finally, estimates using a VAR structure for the overall sample (regression R5), seeking to control for problems such as serial correlation, simultaneity, and possible endogeneity, do not differ substantially. However, they seem to reduce the magnitude of the estimated coefficients, possibly because the VAR model reduces the influence of serial correlation and endogeneity on estimates. Although endogeneity is not considered by OLS, serial correlation is controlled through the Cochrane-Orcutt estimation (see the Durbin-Watson values of around 2). Ultimately, estimates are substantially consistent with the decreasing returns hypothesis and the expected contribution of factors such as knowledge accumulation.

Table 3: Contribution to Economic Growth of Fundamental Factors

\begin{tabular}{|c|c|c|c|c|c|}
\hline \multicolumn{6}{|c|}{ Dependent variable is the log difference GDP per capita 2000-2016: $\log \left(Y_{t}\right)-\log \left(Y_{t,-1}\right)=g$} \\
\hline $\begin{array}{l}\text { Method of re- } \\
\text { gression: }\end{array}$ & $\begin{array}{l}\text { Cross-section re- } \\
\text { gression }\end{array}$ & GLS-Cross & ion weights & & VAR estimates \\
\hline \multirow[t]{2}{*}{ Sample: } & Overall & Overall & $\begin{array}{l}\text { High- } \\
\text { propensity }\end{array}$ & $\begin{array}{l}\text { Low- } \\
\text { propensity }\end{array}$ & Overall \\
\hline & R1 & $\mathrm{R} 2$ & R3 & R4 & R5 \\
\hline $\log \left(\mathrm{Y}_{t,-1}\right)$ & $\begin{array}{l}-0.026 \text { *** } \\
(-11.755)\end{array}$ & $\begin{array}{l}-0.007 * * * \\
(-4.005)\end{array}$ & $\begin{array}{l}-0.013 * * * \\
(-5.715)\end{array}$ & $\begin{array}{l}-0.036 * * * \\
(-6.880)\end{array}$ & $\begin{array}{l}-0.010 * * * \\
(-7.779)\end{array}$ \\
\hline \multirow{2}{*}{$\begin{array}{l}\log (\text { Knowledge } \\
\text { economy index })\end{array}$} & $0.151 * * *$ & $0.187 * * *$ & $0.278 * * *$ & $0.703 * * *$ & $0.185 * * *$ \\
\hline & $(5.457)$ & $(4.345)$ & $(5.829)$ & $(6.588)$ & 4.478) \\
\hline \multirow{2}{*}{$\begin{array}{l}\log (\text { Capital } \\
\text { stock })\end{array}$} & $0.003 *$ & $0.011 * * *$ & $0.011 * * *$ & $0.042 * * *$ & $0.012 * * *$ \\
\hline & $(1.758)$ & $(2.648)$ & $(3.341)$ & $(5.906)$ & $(2.729)$ \\
\hline \multicolumn{6}{|c|}{ Autoregressive terms of the dependent variable (VAR): } \\
\hline$g(-1)$ & & & & & $\begin{array}{l}-0.037 \\
(-0.874)\end{array}$ \\
\hline R-squared & 0.83 & 0.07 & 0.32 & 0.40 & 0.13 \\
\hline Durbin-Watson & 1.96 & 1.83 & 2.12 & 2.15 & \\
\hline $\begin{array}{l}\text { Observations } \\
\text { (after adjust- } \\
\text { ments) }\end{array}$ & 32 & 448 & 75 & 70 & 480 \\
\hline
\end{tabular}

The VAR regression enables observation of a convergence speed of approximately $1.0 \%$ across the 32 Mexican states. Although this is below the OLS estimates, it describes - in relative terms - the recent Mexican experience, which has been defined by slow convergence and low growth rates (for hard data, see this paper's introduction). Based on this work's proposed KAM, the knowledge-capital stock has a positive effect, with a $1 \%$ increase to 
the KEI promoting a $0.18 \%$ increase in economic growth after accounting for initial conditions. This confirms the importance of knowledge in the growth process. However, as a novelty in the convergence field, our analysis indicates knowledge capital has two effects. First, knowledge capital positively impacts economic growth; second, knowledge accumulation helps reduce the gap between regional economies, with more knowledge enhancing growth rates and reducing income inequality, a finding which aligns with the convergence hypothesis.

\section{CONCLUSIONS}

This work's main objective was to build a new method for estimating the knowledge-capital stock in a set of economies. The methodology filters indicators based on the World Bank's pillars through the concept of Euclidian distance, with the intention of precluding the scale or unit of measure of variables from affecting the final index. The Euclidian distance concept satisfies this property. Additionally, the reciprocal function of Euclidian distance interacts with the idea of knowledge accumulation, with larger distances implying a relatively lower knowledge level compared to the leading economy that is used as the measurement benchmark. Thus, economies with larger knowledge-level distances feature smaller estimated values, with smaller distances reflecting a higher estimated knowledge level value. The proposed KAM thus enables regional analyses because the KEI values are comparable in both time and space, a condition often not met in regional contexts. Additionally, this approach does not require additional assumptions about the weight of each pillar in the knowledge formation process.

The empirical exercise estimating the contribution of fundamental factors in the Mexican regions confirms the relevance of the KEI. Estimates of coefficients align with the diminishing returns hypothesis and present the expected signs. Furthermore, the rate of convergence estimate follows both the theory and the empirical evidence. These results confirm the proposed KEI's consistency. Although the estimated effect of the KEI is small, Figures and 4 indicate limited progress for most of the economies during the analysis period, with only Ciudad de México notably accelerating in terms of knowledge accumulation. Given these results, the Mexican government should consider policies reinforcing knowledge capital accumulation across regions to boost the transition to a knowledge economy and consequently improve economic performance.

Nonetheless, the proposal evidently features certain limitations. For instance, it would be desirable to incorporate more variables to more accurately represent the knowledge economy. Additionally, although this work was interested in a broad analysis period, it was only possible to use data reaching back to 2000. Meanwhile, it could be worthwhile considering a different numeraire. For example, a potential level for each variable could be defined, from which distance could be measured. However, defining a maximum acceptable value would be complicated for certain variables.

Finally, in addition to the methodological proposal, this work provides a knowledgecapital database that can be used for future studies. It would be especially useful to apply this approach to other sets of economies, with this methodology's KEI enabling estimate comparisons for other regions and countries. Building upon other work on regional advantage

(C)Southern Regional Science Association 2021. 
(Huggins et al., 2019), this index can usefully explain local knowledge sourcing patterns, which is of critical importance for firms seeking to manage risk and reduce costs.

\section{REFERENCES}

Abdel Fattah, Lara, Giuseppe Arcuri, Aziza Garsaa, and Nadine Levratto. (2020) "Firm Financial Soundness and Knowledge Externalities: A Comparative Regional Analysis," Papers in Regional Science, 99(5), 1459-1486. http://doi.org/10.1111/pirs.12539.

Aum, Sangmin, Sang Yoon Tim Lee, and Yongseok Shin. (2018) "Computerizing Industries and Routinizing Jobs: Explaining Trends in Aggregate Productivity," Journal of Monetary Economics, 97, 1-21. http://doi.org/10.1016/j.jmoneco.2018.05.010.

Badinger, Harald, Werner Müller, and Gabriele Tondl. (2004) "Regional Convergence in the European Union, 1985-1999: A Spatial Dynamic Panel Analysis," Regional Studies, 38(3), 241-253.

Balland, Pierre-Alexandre and David Rigby. (2017) "The Geography of Complex Knowledge," Economic Geography, 93(1), 1-23. http://doi.org/10.1080/00130095.2016.1205947.

Bar, Michael and Oksana Leukhina. (2010) "The Role of Mortality in the Transmission of Knowledge," Journal of Economic Growth, 15(4), 291-321. http://doi.org/10.1007/ s10887-010-9059-5.

Barkhordari, Sajjad, Maryam Fattahi, and Naser Ali Azimi. (2019) "The Impact of Knowledge-based Economy on Growth Performance: Evidence from MENA Countries," Journal of the Knowledge Economy, 10(3), 1168-1182. http://doi.org/10.1007/ s13132-018-0522-4.

Cader, Hanas A. (2008) "The Evolution of the Knowledge Economy," Journal of Regional Analysis and Policy, 38(1100-2016-90010).

Carrion-i Silvestre, Josep and Vicente German-Soto. (2007) "Stochastic Convergence Amongst Mexican States," Regional Studies, 41(4), 531-541. http://doi.org/10.1080/ 00343400601120221.

Caselli, Francesco, Gerardo Esquivel, and Fernando Lefort. (1996) "Reopening the Convergence Debate: A New Look at Cross-country Growth Empirics," Journal of economic growth, 1(3), 363-389. http://doi.org/10.1007/BF00141044.

Chen, Derek HC and Carl J Dahlman. (2005) "The Knowledge Economy, the KAM Methodology and World Bank Operations," World Bank Institute Working Paper, (37256).

Dasgupta, Kunal. (2012) "Learning and Knowledge Diffusion in a Global Economy," Journal of International Economics, 87(2), 323-336. http://doi.org/10.1016/j.jinteco.2011.11.012.

David, Paul A. (2000) "Understanding Digital Technology's Evolution and the Path of Measured Productivity Growth," Understanding the digital economy, pp. 49-95.

Dressler, Marc. (2012) "Assessing the Economic Effects of Patents," Journal of the knowledge economy, 3(3), 294-301. http://doi.org/10.1007/s13132-011-0045-8.

Fan, YH. (2015) "Criteria for Ranking of Nation-States through Regional Knowledge Evaluation," The American Economist, 60(2), 162-175. http://doi.org/10.1177/ 056943451506000206.

Fischer, Manfred M, Thomas Scherngell, and Martin Reismann. (2009) "Knowledge Spillovers and Total Factor Productivity: Evidence Using a Spatial Panel Data Model,"

(C)Southern Regional Science Association 2021. 
Geographical Analysis, 41(2), 204-220. http://doi.org/10.1111/j.1538-4632.2009.00752.x.

Fritsch, Michael and Ronney Aamoucke. (2017) "Fields of Knowledge in Higher Education Institutions, and Innovative Start-ups: An Empirical Investigation," Papers in Regional Science, 96, S1-S27. http://doi.org/10.1111/pirs.12175.

Fritsch, Michael and Viktor Slavtchev. (2010) "How does Industry Specialization Affect the Efficiency of Regional Innovation Systems?," The Annals of Regional Science, 45(1), 87108. http://doi.org/10.1007/s00168-009-0292-9.

German-Soto, Vicente. (2008) "El Stock de Capital Industrial Medido a Través de la Relación Inversión-empleo: Estimaciones para los Estados Mexicanos," Ensayos Revista de Economia, 27(1), 53-80.

Gould, David and Georgi Panterov. (2017) "Multidimensional Connectivity: Why the Interplay of International Connections Matters for Knowledge Transfers," Journal of Policy Modeling, 39(4), 699-711. http://doi.org/10.1016/j.jpolmod.2017.05.017.

Grillitsch, Markus and Magnus Nilsson. (2019) "Knowledge Externalities and Firm Heterogeneity: Effects on High and Low Growth Firms," Papers in Regional Science, 98(1), 93-114. http://doi.org/10.1111/pirs.12342.

Hanushek, Eric A and Ludger Woessmann. (2008) "The Role of Cognitive Skills in Economic Development," Journal of economic literature, 46(3), 607-68. http://doi.org/10.1257/jel. 46.3.607.

$\mathrm{Hu}$, Albert Guangzhou. (2009) "The Regionalization of Knowledge Flows in East Asia: Evidence from Patent Citations Data," World Development, 37(9), 1465-1477. http:// doi.org/10.1016/j.worlddev.2009.01.012.

huallachain, Breandan O. (2007) "Regional Growth in a Knowledge-based Economy," International Regional Science Review, 30(3), 221-248. http://doi.org/10.1177/ 0160017607303047.

Huggins, Robert, Hiro Izushi, and Daniel Prokop. (2019) "Regional Advantage and the Geography of Networks: Explaining Global-local Knowledge Sourcing Patterns," Papers in Regional Science, 98(4), 1567-1584. http://doi.org/10.1111/pirs.12423.

Hunt, Jennifer and Marjolaine Gauthier-Loiselle. (2010) "How Much does Immigration Boost Innovation?," American Economic Journal: Macroeconomics, 2(2), 31-56. http://doi.org/ 10.1257/mac.2.2.31.

Innocenti, Niccolò, Francesco Capone, and Luciana Lazzeretti. (2020) "Knowledge Networks and Industrial Structure for rRegional Innovation: An Analysis of Patents Collaborations in Italy," Papers in Regional Science, 99(1), 55-72. http://doi.org/10.1111/pirs.12478.

Inoue, Hiroyasu, Kentaro Nakajima, and Yukiko Umeno Saito. (2019) "Localization of Collaborations in Knowledge Creation," The Annals of Regional Science, 62(1), 119-140. http://doi.org/10.1007/s00168-018-0889-y.

J Barro, Robert and Xavier Sala-i Martin. (2004) Economic Growth.

Jensen, Hans Siggaard. (2008) "Management and Learning in the Knowledge Society," Journal of Regional Analysis and Policy, 38(1100-2016-90012).

Judson, Ruth. (1998) "Economic Growth and Investment in Education: How Allocation Matters," Journal of Economic Growth, 3(4), 337-359. http://doi.org/10.1023/A: 1009763906365.

Keller, Katarina RI. (2006) "Investment in Primary, Secondary, and Higher Education and the Effects on Economic Growth," Contemporary Economic Policy, 24(1), 18-34. http:

(C)Southern Regional Science Association 2021. 
//doi.org/doi.org/10.1093/cep/byj012.

Kuznetsov, Yevgeny N and Carl J Dahlman. (2008) Mexico's Transition to a Knowledgebased Economy: Challenges and Opportunities. World Bank Publications.

Lenkei, Balint, Ghulam Mustafa, and Michela Vecchi. (2018) "Growth in Emerging Economies: Is There a Role for Education?," Economic Modelling, 73, 240-253. http: //doi.org/10.1016/j.econmod.2018.03.020.

LeSage, James P and Manfred M Fischer. (2009) "The Impact of Knowledge Capital on Regional Total Factor Productivity," Available at SSRN 1088301. http://doi.org/10.2139/ ssrn.1088301.

Lucas, Robert E.. (1988) "On the Mechanics of Economic Development," Journal of Monetary Economics, 22(1), 3-42. http://doi.org/10.1016/0304-3932(88)90168-7.

Lundvall, Bengt-äke and Björn Johnson. (1994) "The Learning Economy," Journal of industry studies, 1(2), 23-42. http://doi.org/10.1080/13662719400000002.

Madsen, Jakob B and Fabrice Murtin. (2017) "British Economic Growth Since 1270: The Role of Education," Journal of Economic Growth, 22(3), 229-272. http://doi.org/10.1007/ s10887-017-9145-z.

Malecki, Edward J. (2010) "Everywhere? The Geography of Knowledge," Journal of Regional Science, 50(1), 493-513. http://doi.org/10.1111/j.1467-9787.2009.00640.x.

Mankiw, N Gregory, David Romer, and David N Weil. (1992) "A Contribution to the Empirics of Economic Growth," The quarterly journal of economics, 107(2), 407-437. http://doi.org/doi.org/10.2307/2118477.

Mexican Institute for Competitiveness, A. C. (IMCO) (2020). (June, 2020) "State Competitiveness Index 2020," Database report.

OECD. (2009) "Innovation and Growth. Chasing a Moving Frontier," International Regional Science Review.

Ojanperä, Sanna, Mark Graham, and Matthew Zook. (2019) "The Digital Knowledge Economy Index: Mapping Content Production," The Journal of Development Studies, 55(12), 2626-2643. http://doi.org/10.1080/00220388.2018.1554208.

Paci, Raffaele and Stefano Usai. (2009) "Knowledge Flows Across European Regions," The Annals of Regional Science, 43(3), 669-690. http://doi.org/doi.org/10.1007/ s00168-008-0256-5.

Rabari, Chirag and Michael Storper. (2015) "The Digital Skin of Cities: Urban Theory and Research in the Age of the Sensored and Metered City, Ubiquitous Computing and Big Data," Cambridge journal of regions, economy and society, 8(1), 27-42. http://doi.org/ 10.1093/cjres/rsu021.

Rim, Gwang-Nam, Gang-Sok Kim, Sun-Hui Hwang, and Un-Dok Ko. (2019) "Some Problems in Statistically Assessing the Level of Knowledge Economy," Journal of the Knowledge Economy, 10(3), 974-996. http://doi.org/10.1007/s13132-017-0510-0.

Romer, Paul M. (1986) "Increasing Returns and Long-run Growth," Journal of political economy, 94(5), 1002-1037. http://doi.org/10.1086/261420.

Romer, Paul M. (1990) "Endogenous Technological Change," Journal of political Economy, 98(5, Part 2), S71-S102. http://doi.org/10.1086/261725.

Schwab, Klaus. (2017) "The Fourth Industrial Revolution, Crown Business," New York, 192.

Sum, Ngai-Ling and Bob Jessop. (2013) "Competitiveness, the Knowledge-based Economy and Higher Education," Journal of the Knowledge Economy, 4(1), 24-44. http://doi.org/

(C)Southern Regional Science Association 2021. 
10.1007/s13132-012-0121-8.

Swamy, Anand V and Brian Fikkert. (2002) "Estimating the Contributions of Capital and Labor to GDP: An Instrumental Variable Approach," Economic Development and Cultural Change, 50(3), 693-708. http://doi.org/10.1086/342250.

van der Wouden, Frank and David L Rigby. (2019) "Co-inventor Networks and Knowledge Production in Specialized and Diversified Cities," Papers in Regional Science, 98(4), 18331853. http://doi.org/10.1111/pirs.12432.

Waldorf, Brigitte S. (2009) "Is Human Capital Accumulation a Self-propelling Process? Comparing Educational Attainment Levels of Movers and Stayers," The Annals of Regional Science, 43(2), 323-344. http://doi.org/10.1007/s00168-008-0225-z.

Wang, Chun-chieh, Mu-hsuan Huang, and Dar-zen Chen. (2012) "The Evolution of Knowledge Spillover and Company Cluster in Semiconductor Industry," Journal of the Knowledge Economy, 3(2), 109-124. http://doi.org/10.1007/s13132-011-0080-5.

Westeren, Knut Ingar. (2008) "How to Define and Measure Knowledge for the Analysis of Competitiveness," Journal of Regional Analysis and Policy, 38(1100-2016-90013).

World-Bank. (2008) "Measuring Knowledge in the World's Economies," .

Yamarik, Steven. (2011) "Human Capital and State-level Economic Growth: What is the Contribution of Schooling?," The Annals of Regional Science, 47(1), 195-211. http://doi. org/10.1007/s00168-010-0365-9.

Zhou, Yuan, Fang Dong, Dejing Kong, and Yufei Liu. (2019) "Unfolding the Convergence Process of Scientific Knowledge for the Early Identification of Emerging Technologies," Technological Forecasting and Social Change, 144, 205-220. http://doi.org/10.1016/j. techfore.2019.03.014.

(C)Southern Regional Science Association 2021. 


\section{APPENDIX}

Table A1: Knowledge Economy Index for the Mexican States in Alphabetical Order, 2000-2016

\begin{tabular}{|c|c|c|c|c|c|c|c|c|c|c|c|c|c|c|c|c|c|c|}
\hline S.N. & Entity & 2000 & 2001 & 2002 & 2003 & 2004 & 2005 & 2006 & 2007 & 2008 & 2009 & 2010 & 2011 & 2012 & 2013 & 2014 & 2015 & 2016 \\
\hline 1 & Aguascalientes & 11.263 & 0.918 & .922 & 10.94 & .263 & 10.914 & 1.026 & 11.05 & 1.019 & 1.267 & 11.278 & 11.67 & 11.578 & 11.377 & 12.043 & 11.659 & 11.468 \\
\hline 2 & Baja California & 1.801 & .305 & .446 & 11.355 & .261 & 10.959 & 11.175 & 11.206 & 0.963 & 1.201 & 11.426 & 11.691 & 11.653 & 11.564 & 11.644 & 11.424 & 11.397 \\
\hline 3 & Baja California Sur & 1.783 & 11.886 & 2.238 & 11.768 & 11.842 & 12.218 & 12.359 & 2.519 & 12.305 & 12.591 & 12.658 & 12.682 & 12.658 & 12.309 & 12.019 & 12.032 & 12.106 \\
\hline 4 & Campeche & 10.369 & 10.363 & 10.436 & 10.451 & 10.401 & 10.411 & 10.582 & 10.528 & 10.475 & 10.599 & 10.676 & 10.846 & 10.874 & 10.891 & 10.765 & 10.801 & 10.727 \\
\hline 5 & Chiapas & 9.479 & 9.589 & 9.587 & 9.63 & 9.599 & 9.527 & 9.633 & 10.158 & 9.719 & 9.856 & 9.944 & 9.94 & 10.327 & 10.176 & 10.238 & 10.155 & 10.068 \\
\hline 6 & Chihuahı & 11.02 & 10.692 & 10.818 & 11.009 & 11.034 & 10.66 & 10.956 & 10.852 & 10.605 & 10.836 & 10.997 & 0.867 & 10.803 & 10.729 & 11.048 & 10.969 & 11.16 \\
\hline 7 & C & 13.737 & 13.804 & 3.615 & 13.521 & 13.633 & 13.371 & 13.571 & 13.632 & 13.546 & 3.671 & 13.604 & 13.904 & 13.66 & 13.472 & 13.625 & 13.566 & 13.576 \\
\hline 8 & Coahuila & 10.917 & 10.912 & 0.897 & 10.978 & 10.969 & 10.863 & 11.045 & 11.095 & 10.952 & 11 & 11.068 & 11.389 & 11.375 & 11.206 & 11.276 & 11.176 & 1.223 \\
\hline 9 & Colima & 10.688 & 10.743 & 10.87 & 11.139 & 11.391 & 11.589 & 11.889 & 11.431 & 11.478 & 1.513 & 11.635 & 11.662 & & 11.45 & 1.557 & 11.502 & 1.364 \\
\hline 10 & Du & 403 & 10.429 & 10.472 & 10.599 & 10.366 & 10.343 & 10. & 10. & 10.438 & 10.309 & 10.596 & & & 10.462 & 10.684 & 10.774 & 0.865 \\
\hline 11 & Guan & 10.536 & 10.62 & 10.573 & 10.693 & 10.6 & 10.421 & 10.439 & 10.534 & 10.402 & 10.65 & 10.543 & 10.924 & & 10.713 & 10.853 & 10.848 & 0.857 \\
\hline 12 & Guerrero & 9.389 & 9.429 & 9.515 & 9.508 & 9.526 & 9.51 & 9.568 & 9.581 & 9.593 & 9.625 & 9.678 & 9.75 & 9.826 & 9.841 & 9.997 & 10.347 & 10.389 \\
\hline 13 & & .07 & 10.132 & 10.164 & 10.625 & 10.31 & & 10.622 & & 10.557 & 10.619 & 10.816 & & & 10.739 & 10.664 & 10.731 & 0.728 \\
\hline 14 & $\mathrm{Ja}$ & 10.893 & 10.698 & 685 & 10.812 & 10.898 & 10.782 & 11 & 11.119 & 10.905 & 0.994 & 11.088 & & & 11.065 & 11.148 & 11.234 & 1.189 \\
\hline 15 & México & 11.157 & 11.08 & 11.014 & 10.938 & 11.285 & 10.905 & 11.031 & 11.04 & 10.95 & 11.094 & 11.31 & 11.421 & 11.298 & 11.102 & 11.156 & 11.115 & 1.126 \\
\hline 16 & $\mathrm{Mi}$ & .818 & 9.863 & 9.946 & 9.906 & 10.043 & 9.987 & 10.013 & 10.388 & 10.096 & 10.146 & 10.247 & 10.577 & 10.59 & 10.467 & 10.234 & 0.241 & 0.186 \\
\hline 17 & Mor & 11.086 & 11.095 & .252 & 11.012 & 11.423 & 11.102 & 11.41 & .546 & 11.277 & 1.406 & 11.415 & 11.895 & 11.801 & 11.61 & 11.541 & 1.498 & 11.333 \\
\hline 18 & Nayari & 10.581 & 10.279 & 10.327 & 10.513 & 10.418 & 10.319 & 10.505 & 10.507 & 10.543 & 10.592 & 10.668 & 10.704 & 10.803 & 10.823 & 10.973 & 10.781 & 10.751 \\
\hline 19 & Nuevo León & 11.574 & 11.598 & 11.467 & 11.621 & 11.344 & 11.473 & 11.568 & 11.645 & 11.532 & 11.607 & 12.008 & 11.716 & 11.599 & 11.631 & 11.777 & 11.808 & 11.78 \\
\hline 20 & Oaxaca & 9.696 & 9.563 & 9.626 & 9.831 & 9.775 & 9.825 & 9.931 & 9.98 & 9.93 & 10.022 & 10.207 & 10.322 & 10.376 & 10.404 & 10.411 & 0.482 & 0.435 \\
\hline 21 & $\mathrm{P}$ & 5 & 10.382 & 9 & 578 & 59 & 10 & 9 & 0.474 & 0.438 & & 10.721 & & 79 & & & 10 & 10.813 \\
\hline 22 & Quer & .124 & 11.108 & 1.065 & 10.966 & 11.045 & 10.953 & 11.268 & 11.495 & 11.412 & 11.691 & 11.48 & 11.594 & 11.436 & 11.485 & 11.538 & 11.681 & 11.61 \\
\hline 23 & & .552 & 11.703 & .596 & 11.726 & 11.801 & 11.691 & 11.857 & 11.706 & 11.293 & 11.615 & 11.637 & 11.726 & 11.766 & 11.565 & 11.979 & 11.556 & 11.435 \\
\hline 24 & San Lui Potosí & 10.405 & 10.362 & 10.393 & 10.996 & 10.76 & 10.614 & 10.459 & 10.565 & 10.59 & 10.606 & 10.733 & 10.83 & 10.846 & 10.708 & 10.842 & 11.168 & 10.895 \\
\hline 25 & Sinaloa & 10.499 & 10.533 & 10.482 & 10.534 & 10.553 & 10.53 & 10.688 & 10.761 & 10.648 & 10.701 & 10.712 & 10.876 & 10.799 & 10.755 & 10.828 & 10.919 & 10.934 \\
\hline 26 & Sonora & 10.95 & 10.821 & 10.801 & 10.924 & 11.226 & 10.867 & 10.965 & 11.038 & 11.033 & 11.016 & 11.214 & 11.305 & 11.311 & 11.226 & 11.355 & 11.235 & 11.141 \\
\hline 27 & Tabasco & 10.122 & 10.161 & 10.203 & 10.256 & 10.316 & 10.261 & 10.605 & 10.575 & 10.527 & 10.6 & 10.629 & 10.77 & 10.743 & 10.708 & 10.802 & 10.784 & 10.725 \\
\hline 28 & & 11.009 & 10.881 & 10.89 & 11.039 & 10.822 & 10.725 & 10.935 & 10.963 & 10.803 & 10.896 & 10.936 & 11.066 & 11.078 & 10.933 & 10.883 & 10.952 & 1.001 \\
\hline 29 & & 10.341 & 10.293 & 10.384 & 10.681 & 10.844 & 10.494 & 10.679 & 10.608 & 10.685 & 10.731 & 10.79 & 10.994 & 10.786 & 10.721 & 10.809 & 10.804 & 10.951 \\
\hline 30 & & 9.992 & 9.975 & 0.068 & 10.411 & 10.403 & 10.221 & 10.14 & 10.23 & 10.566 & 10.668 & 10.763 & & 10.726 & 10.592 & 10.597 & 10.601 & 10.407 \\
\hline 31 & Yucat & 10.846 & 10.668 & & 10.734 & & 10. & & 10.935 & 10.853 & & 11.019 & & 11.24 & 11.106 & 11.257 & 11.168 & 11.174 \\
\hline 32 & Zacatecas & 10.13 & 10.121 & 10.259 & 10.331 & 10.348 & 10.112 & 10.222 & 10.621 & 10.754 & 10.479 & 10.562 & 10.591 & 10.802 & 11.071 & 10.94 & 10.557 & 10.923 \\
\hline
\end{tabular}

(C)Southern Regional Science Association 2021. 